\title{
HUMIDITY CONTROL OF AGRICULTURAL SOIL USING ANALOG MODELING
}

\author{
Rodica VARBAN ${ }^{1}$, Diana MESAROS ${ }^{2}$, Alexandru Marius SILAGHI ${ }^{2}$, Tiberiu COLOSI ${ }^{3}$ \\ ${ }^{1}$ Department of Crops Science, University of Agricultural Sciences and Veterinary Medicine, Calea Manastur nr. 3-5 \\ Cluj-Napoca, Romania \\ E-mail: rodica.varban@usamvcluj.ro \\ ${ }^{2}$ Control Systems Engineering Department, University of Oradea, Str. Universităţii nr. 1, Oradea, Romania \\ E-mail: dsas@uoradea.ro; masilaghi@uoradea.ro \\ ${ }^{3}$ Automation Department, Technical University Cluj-Napoca, Str Memorandumului nr.28 Cluj-Napoca, Romania \\ Tiberiu.Colosi@aut.utcluj.ro
}

\begin{abstract}
This paper presents a simplified version of analog modeling for humidity of an agricultural soil, both isolated and included in a simple control scheme, being emphasized the application aspects for such a system. This article also includes preliminaries for agricultural soil model included in a simple humidity control scheme with some interpretation variants for evolution of processed signals for possible applications.
\end{abstract}

Keywords-Agricultural soil, exponential functions, simplified analog model, computer analog modeling, approximate solutions for second order partial differential equations with two variables

\section{PRELIMINARIES IN ANALOG MODELING OF AGRICULTURAL SOIL}

This paper aims to solve the control scheme presented in figure 1 having in its components the controller $K_{R}$ the actuator $K_{V}$ the negative reaction transducer $K_{N}$ and the analogical model of the agricultural soil [1-4]:

$$
y_{00}(t, s)=K_{y} \cdot F_{00}(t, s) \cdot u_{0}(t)
$$

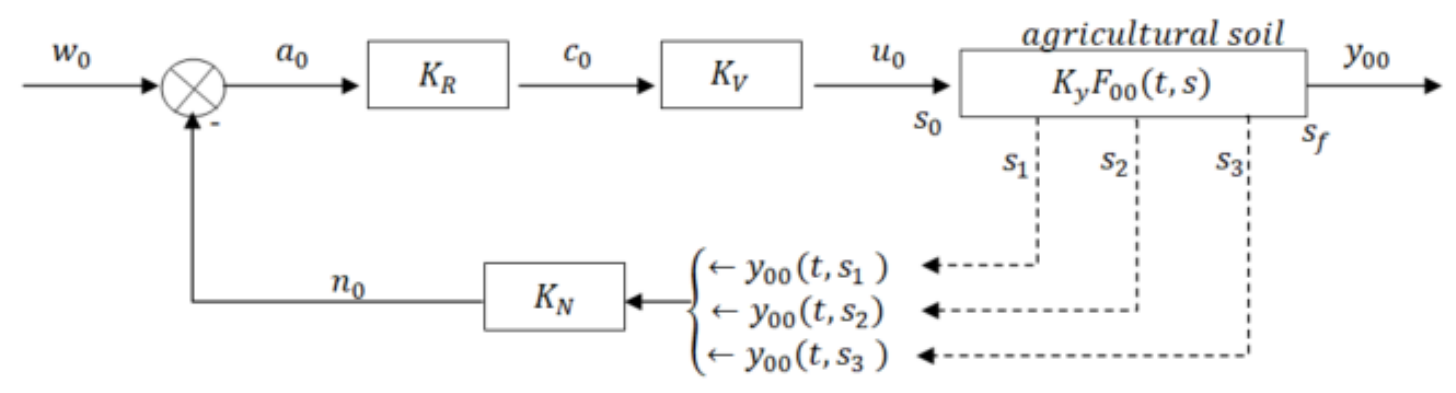

Fig. 1. Analog model for an agricultural soil included in a control scheme

The upper surface of agricultural soil in direct contact with the atmosphere, is considered a square with sides $L=1 \mathrm{~m}$, having the area $L \times l=1 \mathrm{~m}^{2}$ and the final depth on the abscissa $(s)$ equal to $s_{f}=1 \mathrm{~m}$ resulting the volume of agricultural soil: $L^{2} \cdot s_{f}=L^{2} \cdot 1=1 \mathrm{~m}^{3}$. [5-8]

The main goals of this paper are:

- Analog modeling of agricultural soil considered isolated $y_{00}(t, s)=K_{y} \cdot F_{00}(t, s) \cdot u_{0}$

- Analog modeling of the entire equivalent system shown in Figure 1 in which agricultural soil is included in a simple humidity control scheme $y_{00}(t, s)\left[\frac{l}{m^{3}}\right]$

- Interpretation of humidity control performance $y_{00}(t, s)$ at different soil depths $s_{1}, s_{2}, s_{3}$ associated with possible positive results on botanical phenomena;

The analog modeling of the agricultural soil is represented by two exponential functions, one with increasing evolution
$F_{0 T}(t)$ in relation to time $(\mathrm{t})$ and one with decreasing evolution $F_{0 S}(s)$ in relation to the depth of the soil (s) [1-4].

$$
\begin{gathered}
F_{0 T}(t)=1-\frac{T_{1}}{T_{1}-T_{2}} e^{-\left(\frac{t}{T_{1}}\right)}-\frac{T_{2}}{T_{2}-T_{1}} e^{-\left(\frac{t}{T_{2}}\right)} \\
F_{0 S}(s)=\frac{S_{1}}{S_{1}-S_{2}} e^{-\left(\frac{s}{S_{1}}\right)}-\frac{S_{2}}{S_{2}-S_{1}} e^{-\left(\frac{s}{S_{2}}\right)}
\end{gathered}
$$

From relations (2) and (3) results the soil humidity dependent on time $t$ (hours) and depth $s$ (meters) for $\left(s_{0} \leq\right.$ $s \leq s_{f}$ ) represented by the following equation [1-4]:

$$
\begin{aligned}
& y_{00}(t, s)=K_{y} \cdot F_{0 T}(t) \cdot F_{0 S}(s) \cdot u_{0}(t)=F_{00}(t, s) \cdot u_{0}(t)(4) \\
& \text { Where [5-7]: } \\
& \text { - } u_{0}(t) \text { represents the flow on the input surface expressed } \\
& \quad \text { in } u_{0}\left[\frac{l}{m^{2} h}\right] ;
\end{aligned}
$$


- the flow is coming directly either with precipitation or from a water pump included in the actuator $K_{V}$ from figure 1.

The proportionality coefficient $K_{y}$ has the following form[1,2]:

$$
K_{y}=\frac{y_{00}\left[\frac{l}{m^{3}}\right]}{u_{0}\left[\frac{l}{m^{2} h}\right]}=\left[\frac{h}{m}\right]
$$

The choice of time constants $T_{1}, T_{2}$ expressed in hours and the choice of space constants $S_{1}, S_{2}$ expressed in meters is made:

$$
\lambda_{T}=\frac{T_{2}}{T_{1}}=(1,1 \sim 1,9)
$$

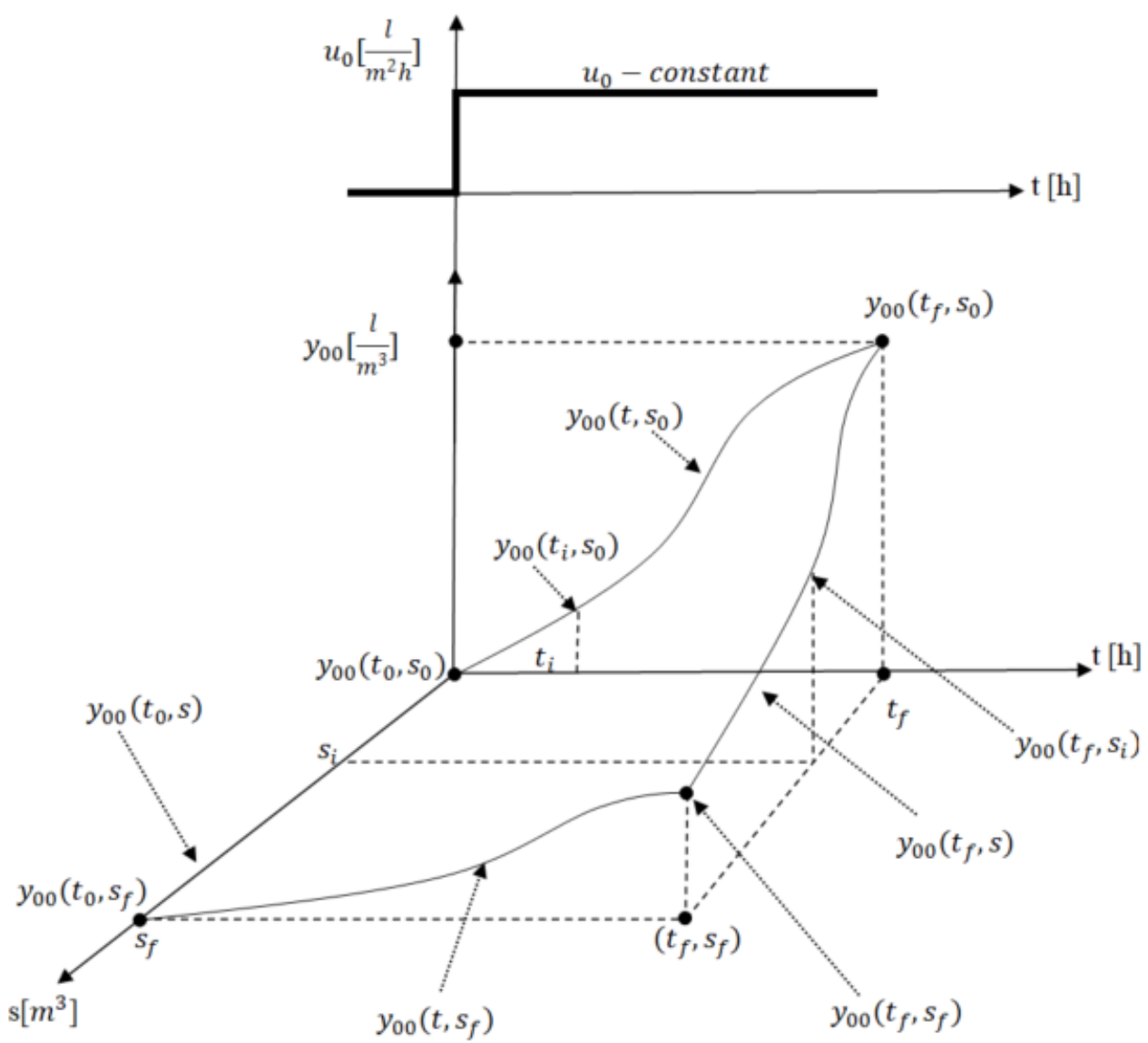

Fig. 2. Analog model for an agricultural soil - humidity propagation in soil depth

In a first stage, the following values are chosen:

- $T_{1}=0.08 t_{f}$;

- $T_{2}=0.17 t_{f}$;

- $S_{1}=0.08 s_{f}$

- $S_{2}=0.17 s_{f}$

Inflection abscissas $t_{i}$ and $s_{i}$ are obtained from the condition of cancellation of second order derivatives [1-4]:

- $\frac{\partial^{2} F_{0 T}(t)}{\partial t^{2}}$

$$
\begin{gathered}
\mu_{T}=\frac{t_{f}}{T_{1}+T_{2}} \\
\lambda_{S}=\frac{s_{2}}{s_{1}}=(1,1 \sim 1,9) \\
\mu_{S}=\frac{s_{f}}{s_{1}+s_{2}}
\end{gathered}
$$

Note that the average values $\lambda \cong 1.5$ and $\mu \cong 4$ are not always common. For the presented case, the final values for time $t_{f}$ are expressed in hours or tens of hours, and for the final depth $s_{f}$ is considered $1 \mathrm{~m}$. 
The two dependencies of the inflection abscissas $t_{i}$ and $s_{i}$ with the final values $t_{f}$ and $s_{f}$ from (12) and (13) become particularly important in experimentally representation of functions $F_{0 T}(t)$ and $F_{0 S}(s)$ from (2), (3) and (4) through three points.

As may be seen in figure 2, the flow on the inlet surface $u_{0}\left[\frac{l}{m^{2} h}\right]$ is considered the step for which the humidity $y_{00}\left(t, s_{0}\right)$ becomes the fastest increasing and the humidity $y_{00}\left(t, s_{f}\right)$ becomes the most attenuated increasing [1,2].

For $y_{00}\left(t_{f}, s\right)$ corresponds the exponentially decreasing humidity as the depth increases from $s_{0}$ to $s_{f}$. In relation to the two abscissas of inflection, $t_{i}$ and $s_{i}$, are also defined the humidity $y_{00}\left(t_{i}, s_{0}\right)$ and humidity $y_{00}\left(t_{f}, s_{i}\right)$.

As a result, the simplified model obtained by experimental measurements falls between a signal $y_{00}(t, s)\left[\frac{l}{m^{2} h}\right]$ representing the water flow on the input surface $u_{0}\left[\frac{l}{m^{2} h}\right]$ and the output signal $y_{00}(t, s)\left[\frac{l}{m^{3}}\right]$ representing the soil humidity.

The simplified model of agricultural soil can also be expressed by the following relation $[1,2]$ :

$$
\begin{aligned}
& y_{00}(t, s)=K_{y} \cdot\left(1-\frac{T_{1}}{T_{1}-T_{2}} e^{-\left(\frac{t}{T_{1}}\right)}-\frac{T_{2}}{T_{2}-T_{1}} e^{-\left(\frac{t}{T_{2}}\right)}\right) . \\
& \left(\frac{S_{1}}{S_{1}-S_{2}} e^{-\left(\frac{s}{S_{1}}\right)}-\frac{S_{2}}{S_{2}-S_{1}} e^{-\left(\frac{s}{S_{2}}\right)}\right) \cdot u_{0}(t)
\end{aligned}
$$

Where:

- $u_{0}(t)\left[\frac{l}{m^{2} h}\right]$ the flow on the inlet surface

- $y_{00}(t, s)\left[\frac{l}{m^{3}}\right]$ soil humidity

- $K_{y}=\left[\frac{h}{m}\right]$ the proportionality coefficient can be interpreted as the time expressed in hours necessary for inlet surface flow $u_{0}(t)\left[\frac{l}{m^{2} h}\right]$ to ensure the humidity $y_{00}(t, s)\left[\frac{l}{m^{3}}\right]$ on the entire depth $s_{f}[m]$ of the soil

\section{AGRICULTURAL SOIL MODELED USING COMPUTER}

For many decades, automated processes from different fields of industry are widely described in literature in order to present the necessity of progress and evolution [5-9].
In order to compute the model of the isolated agricultural soil, the algorithm is implemented in Matlab environment. In the following, the pseudo-code algorithm is presented [1-2]:

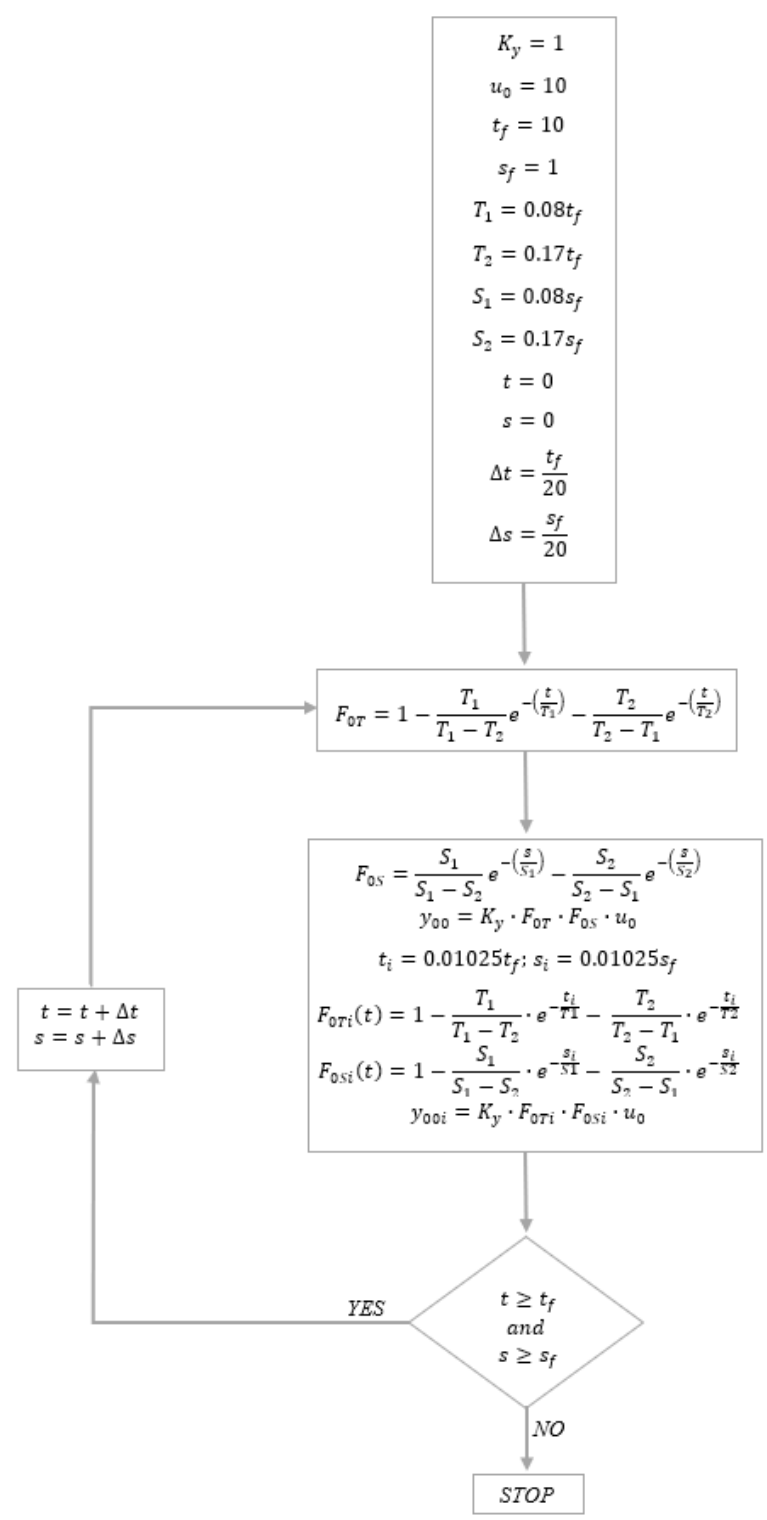

TABLE I. THE OUTPUT RESULTS $y_{00}(t, s)\left[\frac{l}{\mathrm{~m}^{3}}\right]$ AFTER RUNNING THE PROGRAM

\begin{tabular}{|l|l|l|l|l|l|l|l|l|l|l|l|}
\hline $\mathrm{s} \backslash \mathrm{t}$ & 0 & 1 & 2 & 3 & 4 & 5 & 6 & 7 & 8 & 9 & 10 \\
\hline 0 & 0 & 2.05 & 4.90 & 6.97 & 8.26 & 9.02 & 9.45 & 9.69 & 9.82 & 9.90 & 9.95 \\
\hline 0.1 & 0 & 1.63 & 3.89 & 5.54 & 6.56 & 7.16 & 7.50 & 7.69 & 7.80 & 7.86 & 7.90 \\
\hline 0.2 & 0 & 1.048 & 2.499 & 3.553 & 4.210 & 4.595 & 4.815 & 4.939 & 5.000 & 5.046 & 5.068 \\
\hline 0.3 & 0 & 0.622 & 1.484 & 2.118 & 2.508 & 2.728 & 2.859 & 2.933 & 2.937 & 2.996 & 3.010 \\
\hline 0.4 & 0 & 0.357 & 0.851 & 1.210 & 1.434 & 1.566 & 1.641 & 1.683 & 1.706 & 1.719 & 1.727 \\
\hline 0.5 & 0 & 0.201 & 0.480 & 0.683 & 0.810 & 0.884 & 0.926 & 0.950 & 0.963 & 0.971 & 0.975 \\
\hline 0.6 & 0 & 0.113 & 0.269 & 0.382 & 0.453 & 0.495 & 0.519 & 0.532 & 0.539 & 0.543 & 0.546 \\
\hline 0.7 & 0 & 0.063 & 0.1501 & 0.213 & 0.253 & 0.276 & 0.289 & 0.296 & 0.300 & 0.303 & 0.304 \\
\hline 0.8 & 0 & 0.035 & 0.083 & 0.1188 & 0.1400 & 0.153 & 0.161 & 0.1651 & 0.1674 & 0.1687 & 0.1694 \\
\hline
\end{tabular}




\begin{tabular}{|l|l|l|l|l|l|l|l|l|l|l|l|}
\hline 0.9 & 0 & 0.0194 & 0.0464 & 0.0660 & 0.078 & 0.085 & 0.0895 & 0.0918 & 0.0931 & 0.0938 & 0.0942 \\
\hline 1 & 0 & 0.0108 & 0.0258 & 0.0367 & 0.0435 & 0.0497 & 0.0499 & 0.0510 & 0.0517 & 0.0521 & 0.0523 \\
\hline
\end{tabular}

In table 1 are presented the output results after running algorithm. The humidity $y_{00}(t, s=0)$ presents the fastest exponential increase from values 0 to 9.95 meanwhile the humidity $y_{00}\left(t, s_{f}=1\right)$ presents negligible values increasing exponential evolutions from 0 to 0.0523 .

Also, the humidity $y_{00}\left(t_{f}=10, s\right)$ presents a very fast decrease from the value $y_{00}\left(t_{f}, s_{0}\right)=9.95$ to the value $y_{00}\left(t_{f}, s_{f}\right)=0.0523$

For intermediate values these exponential evolutions become progressively attenuated but still increasing for $y_{00}(t, s=$ const $)$ and decreasing for $y_{00}(t=$ const,$s)$.

\section{AGRICULTURAL SOIL INCLUDED IN A SIMPLE CONTROL SCHEME MODELED USING COMPUTER}

Physics, Chemistry, Biology, Microbiology, Electrical machines, Electrochemical and Thermal are just a few fields of industries where analogical modeling methods are used. In these days, when interdisciplinary collaboration represents a must, modeling various types of processes represents a great step. Introducing control automation schemes in various emphasize a great level of innovation research and development [10-16].

The analog model of the agricultural soil presented in the previous chapter was included in a very simple control scheme which contains the controller $\left(K_{R}\right)$, the actuator $\left(K_{V}\right)$ and the transducer $\left(K_{N}\right)$.

Due to the fact that these elements are electronic with negligible inertias with respect to time $\left(T_{1}, T_{2}\right)$ and space $\left(S_{1}, S_{2}\right)$ constants of higher values, these elements tend to be non-inertial.

As a result, transfer functions are no longer used for analog definition and modeling, but a simple system of algebraic relations such as [1-4]:

$$
\left\{\begin{array}{c}
y_{00}=K_{y} \cdot F_{00} \cdot u_{0} \\
u_{0}=K_{V} \cdot c_{0} \\
c_{0}=K_{R} \cdot a_{0} \\
a_{0}=w_{0}-n_{0} \\
n_{0}=K_{N} \cdot y_{00}
\end{array}\right.
$$

In the following it is presented the agricultural soil modeling algorithm included in a simple humidity control scheme $y_{00}(t, s)\left[\frac{l}{m^{3}}\right]$ in relation to the reference signal $w_{0}(t)$ [1-4]:

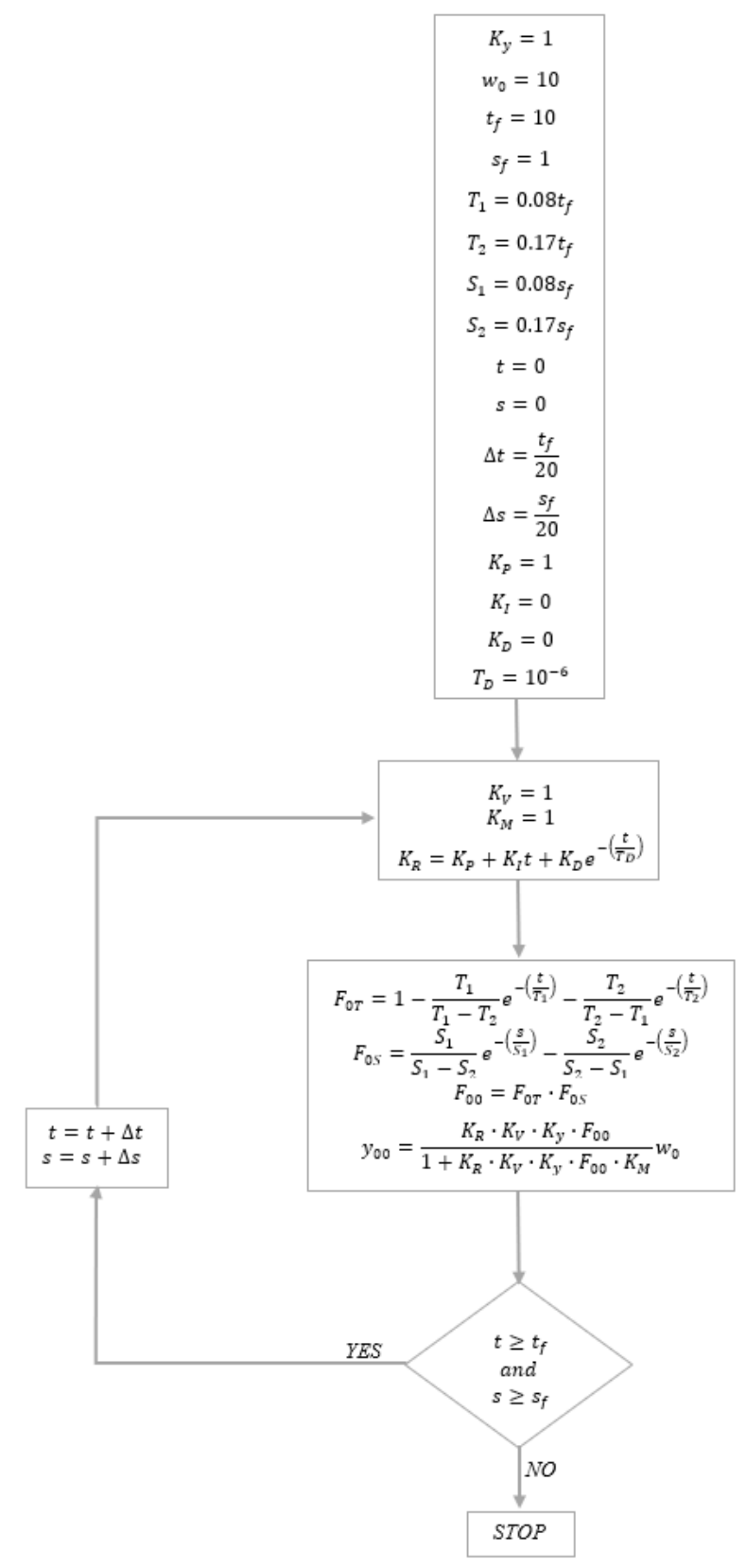

A controlled model $\left(y_{00}\right)$ in relation to reference signal $\left(w_{0}\right)$ after eliminating the reaction signal $\left(n_{0}\right)$, deviation signal $\left(a_{0}\right)$ command signal $\left(c_{0}\right)$ and actuator signal $\left(u_{0}\right)$ is obtained [1-4]:

$$
y_{00}=\frac{K_{R} \cdot K_{V} \cdot K_{y} \cdot F_{00}}{1+K_{R} \cdot K_{V} \cdot K_{y} \cdot F_{00} \cdot K_{N}} w_{0}
$$


In addition to previous chapter, the following notations are considered: $K_{V}=1, K_{N}=1$ and the proportionality coefficient $K_{y}=1$. The following relation is considered for PID controller [1-4]:

$$
K_{R}=K_{P}+K_{I} t+K_{D} e^{-\left(\frac{t}{T_{D}}\right)}
$$

Where:

- $K_{P}$ - proportional effect

- $K_{I}$ - integrative effect in relation to time

- $K_{D}-$ derivative effect in relation to time

- $T_{D}$ - time constant

In the following table are presented the PID control performances ensured at different propagation depth:

TABLE II. PID CONTROL PERFORMANCES ENSURED AT DIFFERENT PROPAGATION DEPTH

\begin{tabular}{|c|l|l|l|l|l|}
\hline$s[m]$ & $s=0$ & $s=0.25$ & $s=0.5$ & $s=0.75$ & $s=1$ \\
\hline$u_{0}\left[\frac{l}{m^{2} h}\right]$ & 9.88 & 24.4 & 87.5 & 253 & 456 \\
\hline$y_{00}\left[\frac{l}{m^{3}}\right]$ & 98.35 & 95.93 & 85.4 & 57.6 & 23.9 \\
\hline
\end{tabular}

Numerous evolutions of the signals $u_{0}$ and the output $y_{00}$ in relation to multitude of parameters from a control scheme can be observed, including through a correlation of PID controller through the proportional integrative derivative effect.

\section{CONCLUSIONS}

The analogical model of the agricultural soil is defined by input $u_{0}\left[\frac{l}{m^{2} h}\right]$ and the output $y_{00}(t, s)\left[\frac{l}{m^{3}}\right]$ represented by the algebraic form $y_{00}=K_{y} \cdot F_{00} \cdot u_{0}$.

In order to obtain accurate results it is necessary to ensure a realistic choice for $K_{y}, u_{0}$, final values $t_{f}, s_{f}$ from which to result the time constants $T_{1}, T_{2}$ and space constants $S_{1}, S_{2}$, as close as possible to humidity properties of the soil in depth.

There is a variaty of associated equipment that may be chosen for transducers, for PID electronic controllers and for the actuator, which may be represented by pumps easily included in control schemes.

An important step is the design and realization of a specialized micro-laboratory for the study of agricultural soils by knowing the phenomena associated between the specific study of humidity and the diversity of plants grown in certain soil humidity conditions.

Fractional Calculus is considered to be used for further development to obtain improved performances of PID controllers using the fractional order derivatives and integrals [7-9].

\section{REFERENCES}

[1] T. Coloşi, M. L. Ungureşan, E. H. Dulf, R. C. Cordoș, "Introduction to Analogical Modeling and Numerical Simulation with (Mpdx) and Taylor Series Distributed Parameters Processes", Editura Galaxia Gutenberg, Cluj-Napoca, Romania, 2009

[2] Coloşi T., Abrudean M., Dulf E., Ungureşan M. L., „Numerical Modelling and Simulation Method with Taylor Series for Lumped and Distributed Parameters Processes“, Editura Mediamira, Cluj-Napoca, ISBN: (10) 973-713-108-8; (13) 978-973-713-108-9, 2006, p. 165

[3] F.Golnaraghi ,C.B. Kuo „Automatic Control Systems”, Editura Wiley, 2009

[4] J. Love , „Proces Automation Handbook”, Editura Springer, 2007

[5] Luca E., V. Budiu, Ciotlăuș A., Hoble A., 2013, Exploatarea sistemelor de imbunatatiri funciare-Irigatii-lucrari practice, Ed. Risoprint ClujNapoca

[6] I Clitan, T Colosi, ML Unguresan, A Codoban, MR Abrudan, "Deformable exponential functions. Case study on propagation phenomena", 2020 IEEE International Conference on Automation, Quality and Testing, Robotics (AQTR), pp. 1-6.

[7] Dulf, Eva-H.; Timis, Daniel; Muresan, Cristina-I., Robust Fractional Order Controllers for Distributed Systems,ACTA POLYTECHNICA HUNGARICA Volume: 14 Issue: 1 Pages: 163-176 Published: 2017

[8] Dulf, Eva-Henrietta, Simplified Fractional Order Controller Design Algorithm, MATHEMATICS Volume: 7 Issue: 12 Article Number: 1166 Published: DEC 2019

[9] Dulf, Eva-Henrietta; Pop, Cristina-Ioana; Dulf, Francisc-Vasile, Fractional calculus in C-13 separation column control, SIGNAL IMAGE AND VIDEO PROCESSING Volume: 6 Issue: 3 Special Issue: SI Pages: 479-485 Published: SEP 2012

[10] Rusu T., I. Bogdan, A.I. Pop, 2012, Indrumator de lucrari practice la Agrotehnica, Ed. Grinta Cluj-Napoca

[11] Muntean L.S., S. Cernea, G.Morar, M.M.Duda, D.I.Vârban, S. Muntean, C. Moldovan, 2014, Ed. Risoprint

[12] Vârban D. I., 2006, Studies of germinative energy and faculty of some species of Echinacea (Echinacea pallida Nutt. and Echinacea purpurea L. Moench), depending on seeds age, 4th Conference on Medicinal and Aromatic Plants of South-East European Countries, Proceedings Iaşi România 28th - 31st of May, ISBN 973-8392-32-2, Alma Mater Publishing House, 283-286;

[13] Vârban D.I., Duda M.M., R. Vârban, S. Oros, 2006. Research concerning the cultivation technology of Angelica archangelica L. specie, its breeding with the help of seedlings. In Scientifical papers Faculty of Agriculture XXXVIII. Ed. Agroprint Timişoara, ISSN 1221-5279, p. 7578;

[14] Vârban D. I., C. Socaciu, M.M. Duda, R. Vârban, S. Muntean, 2010, Research regarding the nutrition space, seeds germination and free compounds in Melissa officinalis L. species, Hop and Medicinal Plants, vol 18, no 1-2, p. 44-48;

[15] Vârban D.I., M.M. Duda, R. Vârban, S. Muntean, 2015, Study of seed germination at Viola tricolor L. (Pansy), Hop and Medicinal Plants, Year XXIII, No. 1-2, p. 52-57;

[16] Vârban R., D. I., Vârban, T. Mihăiescu, F. Păcurar, 2014, Research on the optimisation of Arnica montana L. seedling production, Analele Universităţii din Oradea, Fascicula: Protecţia Mediului, Vol. XXII 2014, pag 157-162. 